\begin{tabular}{l|l} 
Rev Asoc Colomb Dermatol & $\begin{array}{l}\text { Artículo de } \\
\text { Revisión }\end{array}$
\end{tabular}

Fisiopatología del acné

\title{
Aspectos fisiopatológicos del acné
}

Acne, physiopathological aspects

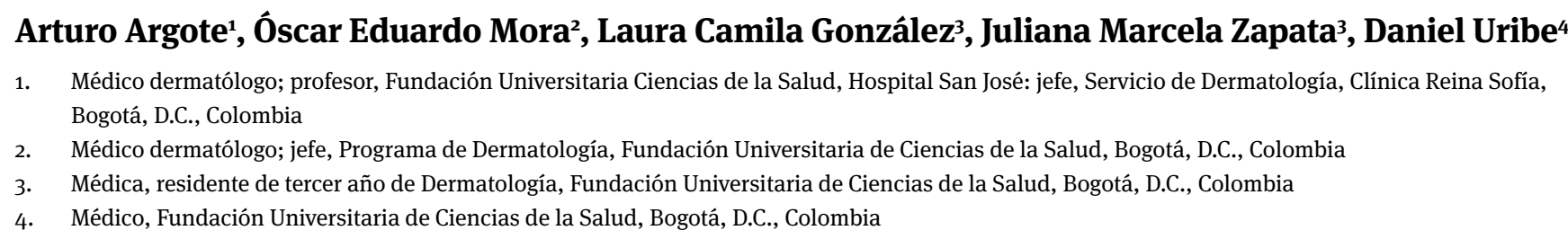

\section{Resumen}

El acné es una de las enfermedades más comunes en la consulta dermatológica, es más frecuente en jóvenes y se caracteriza por la presencia de pápulas, comedones y quistes en cara, pecho y espalda. En este artículo se exponen los mecanismos conocidos de la fisiopatología con énfasis en su aspecto molecular, para un mayor entendimiento por parte del médico clínico, que permitirá un mejor abordaje terapéutico en los pacientes con esta enfermedad.

PALABRAS CLAVE: acné vulgar, fisiopatología, ácido linoleico, receptores toll like, Propionibacterium acnes.

\section{Summary}

Acne is one of the most common pathologies in dermatological practice. It is known for the clinical presence of papules, comedos, and cysts in face, chest and back in young adults and adolescents.

We describe the known physiopathological mechanisms of this disease, with special focus on its molecular aspects. This article will give the clinician a better understanding in this subject, and allow a better approach of his therapeutic decisions on these patients.

KEY WORDS: Acne vulgaris, physiopathology, linoleic acid, toll-like receptors, Propionibacterium acnes.
Correspondencia:

Arturo Argote

Email:

arturoargote@hotmail.com

Recibido 18 de febrero de 2014.

Aceptado:10 de junio de 2014.

No se reportan conflictos de interés.

\section{Introducción}

El acné vulgar es una de las enfermedades inflamatorias más comunes del anexo pilosebáceo. Alrededor del $85 \%$ de los jóvenes entre los 12 y los 25 años la padecen, siendo los hombres los más afectados en este rango de edad. Además, el acné puede continuar en la edad adulta o presentarse a cualquier edad. Se ha estimado que en adultos entre 25 y 34 años, afecta a cerca del 8\%, y en un $3 \%$ a aquellos entre los 35 y 44 años. Hay reportes de una mayor prevalencia en los países desarrollados que en los subdesarrollados, lo cual puede deberse a las escasas publicaciones que se hacen en estos últimos ${ }^{1,2 .}$

La historia natural del acné no se ha establecido en estudios longitudinales; sin embargo, el $60 \%$ de los casos son de resolución espontánea y pueden manejarse con tratamiento tópico de mantenimiento, en el que se usan agentes como antibióticos, peróxido de benzoilo y retinoides 3 .

La isotretinoína oral es el tratamiento más efectivo encontrado hasta el momento y es efectiva en pacientes con acné grave, para evitar recaídas y complicaciones a largo plazo; por lo tanto, un tratamiento temprano y rápido reduce la posibilidad de cicatrices emocionales y físicas ${ }^{2}$. 
Es difícil establecer la frecuencia con la cual se producen secuelas por el acné. Sin embargo, este puede persistir en la edad adulta, especialmente en aquellos individuos que no hayan recibido tratamiento especifico, asociándose a problemas psicológicos como ansiedad, depresión y aislamiento social. Las consecuencias físicas, como la hiperpigmentación persistente y las cicatrices, son comunes y pueden ser difíciles de tratar de manera eficiente ${ }^{2,4}$.

La razón por la cual el acné se convierte en una enfermedad crónica en muchas ocasiones, es difícil de determinar; entre los factores que se han relacionado con la cronicidad del acné se incluyen el estrés, la liberación de andrógenos suprarrenales y ováricos y los antecedentes familiares ${ }^{3,4}$.

En Colombia, el acné es, al menos, una de las primeras cinco dermatosis en la consulta externa. Esto hace que por su frecuencia se le dé bastante importancia en cuanto al dominio que el médico debe tener en relación con su etiopatogenia y, de esta manera, buscar estrategias para su manejo ${ }^{5}$.

Desde hace más de 50 años se han llevado a cabo numerosas investigaciones, las cuales tienen como temas de estudio la epidemiología, la fisiopatología y el tratamiento del acné.

El acné es una enfermedad multifactorial en la que influyen principalmente variables como la hiperqueratinización del infundíbulo folicular, la hipersecreción de sebo por parte de la glándula sebácea, la proliferación aumentada de bacterias residentes normales de la piel como Propionibacterium acnes y el aumento de la respuesta inflamatoria en la unidad folículo sebácea ${ }^{6-8}$.

Gracias al continuo interés científico en entender cada vez más las causas y los mecanismos de las enfermedades, se ha avanzado muchísimo en la investigación sobre la fisiopatología del acné. Se han encontrando incluso múltiples factores que desencadenan la respuesta inflamatoria en la piel, como la activación de los receptores activados de proliferador de peroxisomas (Peroxisome Proliferator-Activated Receptors, PPAR), la activación de los receptores toll like, el estrés oxidativo y la peroxidación lipídica; y otros mecanismos importantes, como el rol de las hormonas, la alteración de la dinámica del queratinocito y el anexo pilosebáceo, el rol de P. acnes en la fisiopatogenia y la alteración de múltiples vías moleculares que contribuyen con la etiología de esta enfermedad ${ }^{3,4,6-8}$.

El objetivo de esta revisión es unificar los conceptos sobre la fisiopatología del acné, con un enfoque en el aspecto molecular, favoreciendo su comprensión y, de esta manera, entender las diferentes modalidades terapéuticas acordes con la enfermedad. Su contenido va dirigido a los residentes y especialistas en dermatología.

\section{Papel de la glándula sebácea}

Las glándulas sebáceas son glándulas holocrinas que se encuentran ubicadas en la dermis superficial y desembocan en el infundíbulo folicular, conformando la unión pilosebácea. Estas juegan un papel muy importante en la patogenia de la enfermedad, no solo contienen las enzimas necesarias para la producción de sebo, sino que, además, tienen la facultad de secretar citocinas y factores de crecimiento que van a influir en la aparición de las lesiones de acné6,9.

La función principal de estas glándulas es producir sebo, esencial para la lubricación, fotoprotección y protección contra la fricción por agentes externos de la piel. Otra importante función del sebo es la de proveer a la piel de sustancias antioxidantes, como la vitamina E y la coenzima Q10, que tienen propiedades proinflamatorias y antiinflamatorias, y protegen la piel del daño oxidativo $0^{6,10,11}$.

Los receptores activados del proliferador de peroxisomas (PPAR), son receptores hormonales nucleares expresados ampliamente en queratinocitos, glandulas sebaceas y sebocitos. Se han implicado en el metabolismo lipídico del sebocito, y en la modulación de la respuesta inflamatoria, convirtiéndose en factores potenciales en el desarrollo del acné. Se han identificado dos tipos de estos receptores nucleares en el sebocito principalmente: PPAR $\alpha$ y PPAR $\gamma$, cuyos ligandos incluyen ácidos grasos (originados del ácido linoleico y el ácido araquidónico, entre otros), eicosanoides, como el leucotrieno $\mathrm{B} 4$, y prostanoides. Todos estos ligandos tienen la capacidad de inducir la lipogénesis en el sebocito ${ }^{11-13}$.

Una vez activados los PPAR por sus ligandos en el núcleo de la célula, y en sinergismo con los receptores $\mathrm{X}$ de retinoides activados, se inicia la transcripción de factores de crecimiento que activan el metabolismo lipídico, y la diferenciación y proliferación del sebocito y del queratinocito ${ }^{2,11,13,14}$.

Se han encontrado bajos niveles de ARNm de PPAR $\gamma$ en sebocitos inmaduros, pero altos niveles en sebocitos bien diferenciados, lo cual demuestra que es de gran importancia en la lipogénesis y maduración del sebocito. Asimismo, la activación del PPAR $\alpha$ aumenta la diferenciación y proliferación del sebocito, y contribuye a la comedogénesis ${ }^{11,12}$.

En diversos estudios se ha demostrado un aumento de la lipooxigenasa 5, presente en las células inflamatorias, implicada en la síntesis del ácido araquidónico y de otros ligandos de los PPAR en la piel con acné en comparación con la piel normal, lo que sugiere un importante papel de los ligandos PPAR en el desarrollo de la enfermedad, promoviendo no solo la proliferación del sebocito y del queratinocito, sino también la amplificación de la respuesta inflamatoria en el acné $e^{11}$. 
El sebo es el producto de la secreción resultante de la desintegración del sebocito y de su contenido en el conducto folicular de la unidad pilosebácea. Está compuesto normalmente por un complejo de diferentes sustancias lipídicas, entre las que se encuentran los triglicéridos y los ácidos grasos saturados (en $57 \%$ de proporción), ésteres de cera (26\%), escualeno (12\%) y ésteres de colesterol $(4,5 \%)^{10,12}$.

Las alteraciones del sebo en los pacientes con acné, se deben a cambios cuantitativos y cualitativos con respecto al de otros pacientes. Aunque la hipersecreción de sebo es muy importante para el desarrollo de esta enfermedad, no es el único factor influyente, y por sí solo no puede desencadenar la enfermedad. Asimismo, se requiere que haya cambios en la composición del sebo para que se produzca el acné ${ }^{10,11}$.

Se ha propuesto que el aumento en la proporción de ácidos grasos monoinsaturados con respecto a ácidos grasos saturados en el sebo, puede ser uno de los factores importantes en la presentación del acné. Normalmente, los ácidos grasos saturados, como el ácido palmítico, son sometidos a una desaturación en su estructura por medio de una enzima conocida como la 6 desaturasa, convirtiéndolos en ácido sapiénico, un acido graso monoinsaturado exclusivo del sebo humano. La alteración en la función de esta enzima, con un consecuente cambio en la proporción de ácidos grasos saturados e insaturados, altera la composición normal del sebo y favorece la enfermedad ${ }^{11,12}$.

En los estudios más conocidos se ha comprobado que en el sebo de los pacientes con acné existe una disminución del ácido linoleico. Este es un ácido graso esencial que no puede ser sintetizado por el ser humano, debe obtenerse en la dieta y se encuentra en alimentos como los aceites vegetales, el pescado, las semillas y las nueces. Una vez ingerido, es esterificado en el enterocito y enviado a la circulación sanguínea en forma de quilomicrones, los cuales son hidrolizados en el endotelio capilar por la lipasa de lipoproteínas, liberando nuevamente al ácido linoleico en el flujo sanguíneo y, de esta forma, incorporándose al sebocito. Este ácido graso es el único que está sometido a beta-oxidación en la glándula sebácea, y cumple un papel muy importante por medio de esta vía metabólica en la producción de lípidos como ésteres de cera y escualeno, componentes normales del sebo humano; además, tiene la capacidad de inhibir la producción de radicales libres de oxígeno ${ }^{3,10,11}$.

La disminución del ácido linoleico en el sebocito no solo altera la composición del sebo, sino que, además, tiene la capacidad de estimular la hiperqueratinización del folículo piloso, crucial en la producción de los comedones ${ }^{3,15,16}$.

Entre los lípidos que tienen un papel importante en la comedogénesis se encuentran los productos de peroxidación de los lípidos en el sebo, específicamente los productos de peroxidación del escualeno (monohidroperóxido de escualeno). Aunque se desconoce la razón específica por la que hay una importante acumulación de escualeno en la glándula sebácea, se sabe que después de la exposición a los rayos ultravioleta, el escualeno sufre una fotodegradación masiva que conlleva el estrés oxidativo y posteriortemente su peroxidación, lo que resulta ser un factor comedogénico conocido ${ }^{11,15}$.

Se ha encontrado una relación directamente proporcional entre la cantidad de monohidroperóxido de escualeno y el tamaño de los comedones, así como también se ha demostrado que este compuesto estimula la hiperproliferación de queratinocitos, la activación de cascadas inflamatorias y la activación de receptores activados de proliferador de peroxisomas. A su vez, se sabe que los pacientes con acné que tienen concentraciones aumentadas de los productos de peroxidación de los lípidos, y presentan una disminución significativa de las concentraciones de antioxidantes naturales cutáneos de la superficie de la piel ${ }^{10-13}$.

Los radicales libres de oxígeno son producidos por la reducción del oxígeno. La producción de radicales libres es lenta, y estos se eliminan por enzimas antioxidantes intracelulares como la superóxido dismutasa, la catalasa y la glucosa-6-fosfato deshidrogenasa ${ }^{17,18}$.

El malondialdehído es el producto final de la peroxidación lipídica. Si las enzimas antioxidantes se vuelven incapaces de controlar el daño oxidativo, los radicales libres de oxígeno inician este proceso en las membranas celulares y organelas, estimulando la irritación y destrucción del tejido sano alrededor del folículo, lo cual favorece los eventos inflamatorios observados en el acné $e^{19-24}$.

\section{Inflamación y acné}

Se ha observado aumento de interleucina $1 \alpha$ (IL-1 $\alpha$ ) en los pacientes con acné; esta se considera un factor de activación de la cascada inflamatoria que induce la expresión de moléculas de adhesión, como molécula de adhesión intercelular-1 (ICAM-1), E selectina, molécula de adhesión vascular (VCAM) ${ }^{9-11}$, e indirectamente, contribuye a la migración de monocitos a la dermis perifolicular. La IL-1 $\alpha$ es, entonces, el estímulo para una respuesta inmunitaria innata. Entre los factores responsables del aumento de su expresión, se encuentra la disminución de ácido linoleico en los folículos, lo que produce una alteración en la función de barrera la cual estimula la liberación de sustancias proinflamatorias a partir de queratinocitos epiteliales y una pérdida transepidérmica de agua en la luz del folículo, promoviendo un cambio en el microambiente del conducto que favorece el crecimiento y la proliferación de $P$. acnes s,11,15,22,24-26. $^{2}$.

Existen fuertes implicaciones de la participación de 
P. acnes para iniciar la respuesta inmunitaria adaptativa en la enfermedad; entre ellas, una sugiere que sus antígenos solubles estimulan una respuesta mediada por los linfocitos $\mathrm{T}^{1}$. Por otro lado, se dice que la parte inferior del infundíbulo solo tiene un espesor de dos a tres capas de células, y que la pared es relativamente frágil, por lo que en esta ubicación se pueden facilitar las interacciones entre $P$. acnes y las células de Langerhans, seguida por la presentación y estimulación de las células T CD4 (T helper 1) dentro de la piel y con esto las transcripciones de las citocinas como la interleucina 12 (IL12), el factor de necrosis tumoral (TNF- $\beta$ ), el interferón gamma (IFN $\gamma$ ), el factor estimulador de colonias-granulocito macrófago (GM-CSF) y el factor de crecimiento epidérmico (EGF), citocinas que son efectoras de la respuesta inmunitaria adaptativa ${ }^{4,22,27,28}$.

Se ha establecido que en el acné la inflamación se produce antes que la hiperproliferación de la pared del folículo. En biopsias de piel en casos de acné, en folículos no afectados se ha observado un infiltrado inflamatorio conformado por células $\mathrm{T}$ helper $\mathrm{CD} 4$ de memoria, macrófagos no activados y disminución de las células de Langerhans, que indicaría una migración de estas células a los ganglios linfáticos de drenaje de la piel. Estas observaciones se encuentran en asociación con aumento en los vasos dérmicos, mayor expresión de $\alpha$ V integrina, una señal para el inicio de la angiogénesis y para el aumento de la expresión de moléculas de adhesión como VCAM-1, E-selectina (conocida como el ligando del antígeno linfocítico cutáneo) e ICAM-1, que facilitan el reclutamiento y la migración de las células inflamatorias a la dermis. Asimismo, se ha observado disminución de los neutrófilos en el infiltrado inflamatorio de las lesiones iniciales, lo que indica que la inflamación se inicia por células T CD4 como respuesta a una estimulación antigénica ${ }^{8,25}$.

La ausencia de hiperproliferación en las lesiones tempranas sugiere que existe un evento subclínico inflamatorio previo a los eventos hiperproliferativos desencadenados por una respuesta inmunitaria innata que, posteriormente, se transforma en una respuesta inmunitaria adaptativa ${ }^{22,29}$.

\section{Papel de Propionibacterium}

\section{acnes}

Propionibacterium acnes es una bacteria anaerobia Gram positiva que se encuentra como flora normal en la piel, especialmente en el folículo pilosebáceo. Se ha observado que los pacientes que padecen acné tienen un mayor número de esta bacteria, y la reducción en su po- blación se relaciona con mejoría clínica ${ }^{30}$. Por este motivo, los agentes antimicrobianos y antibióticos han sido un pilar en el tratamiento del acné. Sin embargo, cada vez se observa más resistencia antibiótica por parte de P. acnes debido a la producción de la biopelícula y la incapacidad de neutrófilos y macrófagos para fagocitarla. Dicho en otros términos, la biopelícula excretada por $P$. acnes es un polímero (glucocáliz) que favorece la supervivencia y la capacidad inmunogénica y que da como resultado la resistencia a los antibióticos, hecho que limita la efectividad del tratamiento ${ }^{19,21,30}$.

Propionibacterium acnes juega un papel importante, tanto directa como indirectamente, en el desarrollo del acné inflamatorio. Un aumento excesivo de esta bacteria contribuye a la precipitación de la respuesta inmunitaria innata y, en algunos casos, puede presentarse ruptura folicular e iniciarse una reacción inflamatoria que conlleva la aparición de pápulas, nódulos o quistes ${ }^{13}$.

De igual manera, $P$. acnes produce lipasas que favorecen la liberación de ácidos grasos a partir del estrés oxidativo. Los ácidos grasos libres por encima de una cierta concentración son irritantes y proinflamatorios. Más tarde, otros metabolitos potencialmente inflamatorios, como las proteasas, las hialorunidasas y factores quimiotácticos, pueden atraer los neutrófilos y dar origen a un infiltrado inflamatorio en la pared folicular y en la dermis circundante, esto, asociado a la presencia de macrófagos que entran al folículo y fagocitan a $P$. acnes, estimula la liberación de sustancias hidrolíticas que amplifican más la reacción inflamatoria ${ }^{19,28,30,31}$.

Esta bacteria tiene la capacidad de estimular también los TLR 2, que induce en los monocitos y otras células inflamatorias la producción de mas citocinas, entre ellas la IL 8, la cual quimiotácticamente atrae más células inflamatorias y se perpetúa la respuesta. Esta bacteria, por una parte, estimula tanto las vías clásicas como las alternas del complemento y, por otra, fomenta la respuesta innata en el huésped, la cual posteriormente termina en una respuesta adaptativa en la que se manifiesta como un sistema inmunitario antígeno específico ${ }^{32}$.

Los receptores de tipo toll son una familia de proteínas transmembrana de tipo I que forman parte del sistema inmunitario innato y posibilitan la adaptación del sistema inmunitario. Son los responsables de varias vías de patrones de reconocimiento de patógenos (PathogenAssociated Molecular Patterns, PAMPS) expresados por un amplio espectro de agentes infecciosos. Los receptores de tipo toll están presentes en monocitos, macrófagos, neutrófilos, células de Langerhans, linfocitos T y linfocitos B, células sebáceas, queratinocitos y células endoteliales ${ }^{32,33}$.

Las proteínas de los receptores de tipo toll tienen una porción extracelular rica en leucina y una porción ci- 
toplásmica que tiene homología con el receptor IL-1 de tipo I. Los estudios con varios receptores de tipo toll demuestran que activan la vía del NF-kB, y regulan la expresión de citocinas, mediante varias moléculas, incluyendo el MyD88, TIRAP/Mai y TRF. La activación de la vía del NF-kB conduce a la iniciación de la respuesta adaptativa inmunitaria por la producción de citocinas inflamatorias, tales como al IL-1, IL-8, TNF-alfa, IL-12, y la inducción de moléculas de adhesión ${ }^{32,33}$.

En particular, los queratinocitos y los sebocitos de la unidad pilosebácea pueden ser activados por $P$. acnes por medio de los receptores de tipo toll. Estos también se expresan en la superficie de algunos macrófagos que rodean la unidad pilosebácea en el acné. Propionibacterium acnes ha mostrado inducir la producción de IL $2 \mathrm{e}$ IL 8 mediante vías dependientes de TLR 2 (32).

El efecto de $P$. acnes y la activación de los receptores de tipo toll en los queratinocitos, han sido bien estudiados. Los TLR2 y TLR4 expresados en los queratinocitos son los responsables primarios del reconocimiento de peptidoglucanos y lipopolisacáridos, respectivamente. Se ha visto in vivo que la expresión de TLR2 y TLR4 está aumentada en la epidermis con lesiones de acné; además, se ha visto que in vitro favorecen la producción de metaloproteinasas (MMP) por parte de los queratinocitos. Las MMP (colagenasas, gelatinasas, estromelisinas, matrilisinas) son endopeptidasas producidas por diferentes tipos de células, incluyendo los queratinocitos, y son capaces de romper los componentes de la matriz extracelular. Están implicadas en trastornos hiperproliferativos, de remodelación e inflamatorios de la piel. En el acné se promueve la producción de MMP 9 por parte de los queratinocitos y los sebocitos ${ }^{27,32}$.

Propionibacterium acnes también provoca la secreción de péptidos antimicrobianos y citocinas por los queratinocitos como las $\beta$ defensinas, IL1, TNF $\alpha$ y GM-CSF. Por otro lado, se han identificado varios componentes celulares de P. acnes, como GroEl, una proteína de choque térmico (HSP), y Dnak, un lipoglucano. Ambas proteínas actúan como reguladoras positivas de la producción de citocinas por los queratinocitos. Estas proteínas de choque térmico son muy parecidas a las de choque térmico de los humanos (HSP 60), pudiendo causar un tipo de reacción cruzada que estimula el sistema inmunitario, promoviendo de esta manera las bases para la autoinmunidad. Por lo tanto, las proteínas de choque o los lipoglucanos pueden actuar como ligandos para los receptores de tipo toll ${ }^{32,33}$.

Estas observaciones proporcionan apoyo lógico para el uso de esquemas antiinflamatorios, como bloqueadores de TLR2, en el tratamiento del acné. El tratamiento primario en monocitos humanos con ácido transretinoico disminuye la expresión de receptores de tipo toll. El ácido transretinoico es capaz de reducir las citocinas que inducen P. acnes, como IL 12 Y TNF $\alpha$. (Las tetraciclinas no solo actúan directamente sobre P. acnes sino que también disminuyen la producción de ácidos grasos libres, importantes irritantes y promotores de la respuesta inflamatoria ${ }^{4,27,32-34}$.

\section{Efecto de las hormonas en el}

\section{acné}

Los andrógenos juegan un papel muy importante en la fisiopatogenia del acné. Se ha comprobado que para que se produzca la enfermedad, estos deben estar presentes, y debe existir previamente un desarrollo normal de la glándula sebácea, el cual está mediado por estas hormonas ${ }^{23,35-37}$.

Se han medido los niveles de testosterona en mujeres con acné, los cuales se encuentran elevados con respecto a aquellas sanas, pero característicamente persisten dentro de límites normales; esto sugiere que no solo son importantes las concentraciones de andrógenos, sino también, la sensibilidad de cada paciente a ellos ${ }^{35,38}$.

Aunque en su mayoría los andrógenos son producidos por las glándulas suprarrenales y ovarios, también pueden sintetizarse localmente en la glándula sebácea a partir de la dehidroepiandrostenediona (DHEAS) circulante en la sangre. En la glándula sebácea se han identificado enzimas que participan en la síntesis de andrógenos, como la 3 beta-hidroxiesteroide-deshidrogenasa, la 17 beta- hidroxiesteroide-deshidrogenasa y la 5 alfareductasa de tipo 1 , que confirma la síntesis a este nivel de androstenediona, testosterona y dihidrotestosterona (DHT). En varios estudios se ha confirmado un aumento en las concentraciones y en la actividad de la enzima 5 alfa-reductasa 1 en las áreas corporales donde se pre-

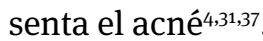

La testosterona y la DHT son los dos andrógenos más influyentes en la función de la glándula sebácea. Estas dos hormonas atraviesan la membrana celular para unirse con los receptores androgénicos localizados en la membrana nuclear celular, donde la DHT presenta una avidez 5 a 10 veces mayor por este receptor que la testosterona. Las células blanco donde se da lugar la unión del andrógeno con el receptor son los sebocitos, células epiteliales de los conductos ecrinos, células foliculares de la papila dérmica y queratinocitos del conducto sebáceo ${ }^{6,39}$.

El complejo receptor-andrógeno interactúa con el ADN del sebocito y el queratinocito donde regula genes implicados en la proliferación celular. Aunque no se conoce 
exactamente cuáles genes específicos son el blanco de los andrógenos en la glándula sebácea, sí se sabe que estos incluyen genes que codifican para factores de crecimiento y enzimas lipogénicas, estimulando la producción de ácidos grasos y hormonas esteroideas, la secreción de sebo, y la proliferación y diferenciación del sebocito ${ }^{33,38,39}$.

Adicionalmente, se ha reportado la asociación de la hormona del crecimiento, la insulina y el factor de crecimiento similar a la insulina 1 (IGF1), con la patogénesis del acné. Estas hormonas tienen diferentes efectos sobre el crecimiento y la proliferación del sebocito. La hormona del crecimiento secretada por la hipófisis anterior, induce la síntesis hepática de IGF1, que actúa como factor de crecimiento ${ }^{3,10}$.

La IGF1 se une a su receptor (IGF1R) y menos fuertemente al receptor de la insulina, en las células sebáceas y queratinocitos de los conductos, y activa cascadas de señalización de proliferación celular, como la RAS-RAFMAP y la del fosfatidil-inositol-trifosfato (IP3). Estas vías tienen múltiples efectos en el sebocito, entre los que se destacan la inducción de lipogénesis, la expresión de las proteínas de unión al elemento de respuesta de los esteroles (SREPB1) que a su vez regulan la producción de ácidos grasos, y la proliferación del queratinocito y del sebocito ${ }^{10}$.

En varios estudios se ha demostrado que la adición de IGF1 a cultivos de piel humana y de rata, ha aumentado la actividad de la 5 alfa-reductasa, lo que señala a la IGF1 como un amplificador del metabolismo androgénico periférico ${ }^{3,40}$.

\section{Dieta y acné}

Debido a estos avances en el conocimiento de la enfermedad, y a estudios en pacientes con hábitos de dieta hiperglucémica, se ha establecido que las dietas ricas en carbohidratos se asocian a hiperglucemia, hiperinsulinemia $\mathrm{y}$, por consiguiente, aumento en la producción de IGF1, que favorece la aparición del acné. En otros estudios se ha demostrado que el consumo de leche aumenta la producción de IGF1, secundario a la elevación sanguínea de la glucemia después del consumo, con elevación posterior de la insulina y producción de IGF1, lo que podría ser un disparador de las lesiones en piel. Sin embargo, la mayoría de expertos opinan que pese a estos esfuerzos, todavía no hay datos suficientes, ni concluyentes basados en evidencia científica para apoyar dicha asociación que permitan aclarar con exactitud el papel de la nutrición en el acné 41-43. $^{-1}$.

\section{Otros factores}

Recientemente se han visto implicados en la patogénesis del acné varios neuropéptidos, como la corticoliberina (CRH), las melanocortinas y la sustancia P.

En lesiones de acné, se ha encontrado aumento en las endopeptidasas (dipeptidil-peptidasa IV y aminopeptidasa $\mathrm{N}$ ), encargadas de degradar la sustancia $\mathrm{P}$ en los sebocitos humanos. La inhibición de estas peptidasas suprime la proliferación y la producción de sebo, y estimula la diferenciación del sebocito, que podría ser de utilidad en el futuro para nuevos tratamientos ${ }^{10,23 .}$

La membrana del sebocito presenta receptores de tipo 1 y 2 para la CRH, que estimulan la producción de lípidos en la glándula sebácea, y la secreción de IL 6 e IL 8 por parte del sebocito; además, tiene la capacidad de incrementar la activación de andrógenos al sintetizar deshidrogenasa 5'3 beta-hidroxiesteroide, encargada de convertir DHEAS en testosterona.

Estos hallazgos concuerdan con el aumento de la CRH en sebocitos de pacientes con acné $\mathrm{e}^{10,23,39}$.

Aunque en el momento no se conoce cuál es el papel concreto de la hormona alfa melanotropina (MSH) en el acné, sí se sabe que existe un aumento de sus receptores MC-R1 en comparación con los sebocitos de piel sana. En condiciones normales, la MSH alfa estimula la diferenciación del sebocito y la lipogénesis ${ }^{23}$.

\section{Hiperqueratinización del folículo}

El receptor del factor de crecimiento de fibroblastos 2 (FGFR2B) que se encuentra en queratinocitos y sebocitos, es un regulador de la diferenciación del queratinocito; este comparte vías de señalización con el IGF1R. El FGFR2B cumple un papel muy importante en la diferenciación del queratinocito, estimulando su proliferación y, por consiguiente, en la hiperqueratinización del folículo. Este efecto promotor del acné esta mediado por factores de crecimiento fibroblástico dependientes de andrógenos y también del IGF1, que se unen al FGFR2B, estimulando la comedogénesis ${ }^{44,45}$.

Se han demostrado mutaciones en el gen de FGFR2B, que aumentan la función y estimulan la proliferación del queratinocito; que explicarían el acné en pacientes con síndrome de Apert (síndrome de acrocefalosindactilia) y también podrían estar implicadas en la patogenia del acné ${ }^{43,44}$.

Así mismo, se sabe que el factor de crecimiento epidérmico (EGF) ejerciendo sus acciones a través de un receptor especifico, expresado en queratinocitos basales 